\title{
Dengue Associated Hemophagocytic Lymphohistiocytosis
}

\author{
Krishna Chaitanya $^{1}$ (D) $\cdot$ Sandeep Karanam ${ }^{1} \cdot$ Kiran Kumar $^{1}$
}

Received: 28 September 2019 / Accepted: 17 December 2019 / Published online: 3 January 2020

(C) Dr. K C Chaudhuri Foundation 2020

To the Editor: Hemophagocytic lymphohistiocytosis (HLH) is a potentially life-threatening rare macrophage related hyper inflammatory disorder that presents as prolonged fever and a sepsis like syndrome [1]. HLH secondary to infections is the commonest, especially in tropical countries. The clinical features are: fever, hepatosplenomegaly, multiorgan dysfunction and pancytopenia resembling severe sepsis [2]. There are limited studies over HLH associated with Dengue from India.

Children from both gender of $>1 \mathrm{y}$ to $<18 \mathrm{y}$ with NS1 and serologically IgM confirmed dengue infection admitted at Paramita Childrens Hospital, Hyderabad during the outbreak season (June 2019 through September 2019) were reviewed. They were given supportive therapy in form of IV fluids, blood component transfusions and high flow nasal oxygen as and when required. We had 9 cases of HLH among 950 admitted dengue patients over a time period of 3 mo. They were treated with inj. dexamethasone initially and later switched to oral for $21 \mathrm{~d}$.

In our study, incidence of HLH was $0.01 \%$; persistent fever along with pancytopenia occurred in all $(n=9)$ of them, $7(77 \%)$ had refractory pleural effusion and deranged liver function tests and one (11\%) child required mechanical ventilation and $8(88 \%)$ had organomegaly. Six children (66\%) were diagnosed clinically based on criteria laid down by the Histiocytic Society in 2004 and 2018 [1, 2], but bone marrow aspiration (BMA) was required for $3(33 \%)$ who showed hemophagocytes. In all (100\%) children, fever subsided within $48-72 \mathrm{~h}$ of starting steroids; reversal of cytopenias occurred within $48 \mathrm{~h}$ for $6(66 \%)$ of them and regression of hepato-splenomegaly occurred over the next 3-4 d. IVIG was used $(1 \mathrm{~g} / \mathrm{kg})$ in two children as they did not show any improvement after $48 \mathrm{~h}$ of starting steroids. Our findings are comparable with findings of Pal et al. [3], Umar et al. [4] and Bhattacharya et al. [5].

HLH is a life-threatening complication of Dengue fever which should be kept in mind while dealing with worsening or refractory dengue cases beyond 9th day of illness as early identification and treatment would improve overall prognosis.

\section{Compliance with Ethical Standards}

Conflict of Interest None.

\section{References}

1. Henter JI, Horne A, Arico M, et al. HLH-2004: diagnostic and therapeutic guidelines for hemophagocytic lymphohistiocytosis. Pediatr Blood Cancer. 2007;48:124-31.

2. UpToDate [Internet]. Uptodate.com. 2019. Available at: https:// www.uptodate.com/contents/clinical-features-and-diagnosis-ofhemophagocytic-lymphohistiocytosis. Accessed on 21 November 2019

3. Pal P, Giri PP, Ramanan AV. Dengue associated hemophagocytic lymphohistiocytosis: a case series. Indian Pediatr. 2014;51:496-7.

4. Umar MM, Padmasani VR, Vidya K, Rajakumar PS. G164(P) dengue associated hemophagocytic lymphohistiocytosis. Arch Dis Child. 2019;104:A66.3-7.

5. Bhattacharya D, Angurana SK, Nallasamy K, Iyer R, Jayashree M. Severe dengue and associated hemophagocytic lymphohistiocytosis in PICU. Indian J Pediatr. 2019;86:1094-8.

Publisher's Note Springer Nature remains neutral with regard to jurisdictional claims in published maps and institutional affiliations.

Krishna Chaitanya

dkrishnac7@gmail.com

1 Department of Pediatric Intensive Care Unit, Paramitha Childrens Hospital, Hyderabad, Telangana, India 